\title{
The Role of AIB and IB in a De-Globalizing World
}

\author{
Martin Kaspar, Durham University, UK
}

At the 2017 AIB conference in Dubai, two themes seemed to dominate the debate, either as dedicated panel-topics or as implicit subtext of many sessions: the questions of (a) are we living in an era that is rapidly de-globalizing and, the-seemingly unrelated-question of, (b) whether IB is in the process of losing its relevance.

It could be argued that there is probably an element of truth in both statements, that both questions are more interconnected than it appears at first sight, and that the potential threat of a de-globalizing world might even strengthen the role of IB in the future.

We will discuss each of these two questions in turn, outline where they are connected, and explain how this could lead to a more central role of IB in the near future.

\section{Are We Living in an Era That Is Rapidly De-Globalizing?}

Whether we are indeed experiencing a gradual—or even rapid-de-globalization is a difficult question to answer. Judging by the number of panels and session-headlines at this years' AIB conference, one could certainly get this impression: "Globalization under threat: how should IB respond?" "Business in a less globalized world-where to go from here?" or "De-globalization: lessons from history."

Similarly, many publications-academic and non-academic - point in this direction; to illustrate, we would only like to point to a few examples, such as Sauvant (2013) who, citing UNCTAD figures, pointed out that we observe a continuous rise of policy measures and FDI regulations which make investment climates less welcoming. Or Abbosh et al. (2017), who observed that barriers for trade and investment to cross borders are increasing (e.g., "the number of trade-restrictive measures in the G20 nations almost quadrupled from 324 in 2010 to 1,263 in 2016).

There are individual aspects which collectively paint a darker picture, as outlined by Boddewyn and Rottig (2017), e.g., less international business, guarded globalization of emerging markets and the anti-globalization movements in developed counties, or Witt's (2017) observation that the big internationalization-policy-projects are in trouble. WTO negotiations for trade liberalization (the "Doha Round") ended in failure, TPP has been abandoned, and NAFTA is questioned by a US president who is an outspoken opponent of free trade and open borders. Even the vociferously "Pro-Free-trade nations"-Canada and the EU member states-barely managed to push the Comprehensive Economic and Trade Agreement (CETA) through against the vocal protest of their own populations. Hence, as Witt (2017) so poignantly remarked, globalization, which for a quarter of a century seemed unstoppable, increasingly "looks more vulnerable than inexorable."

But while the "anti-globalization narrative" sounds intuitively plausible, and the seeming slowing down of goods, services, and investments crossing national borders apparently confirms this, there are other narratives, rarely heard, but maybe equally plausible. Maybe the slowing numbers of goods crossing our borders is based on something other than the world entering a new era of isolationism and economic nationalism?

It could be argued, that this is the inevitable slow-down of a several decade long off-shoring process. The diminishing-return curve or saturation point, where all companies who wanted to re-locate production to low cost countries have eventually done so. Or we over-state the seriousness of the slowing-down of globalization due to inaccuracies of the figures on which we 
base this assumption. BOP figures are famously problematic in measuring FDI activities (Beugelsdijk et al., 2010). Not to mention national specifics which make FDI figures hard to interpret (Sutherland \& Anderson, 2015).

Our observations could be biased given the relatively high cutoff points introduced for BOP reporting, an effect which not only could distort figures due to the change in reporting standards but also on account of the fact that most of the large MNCs already enjoy a global presence - and that it is arguably now small and medium-sized enterprises (SMEs) who are globalizing. With the high cut-off points we are potentially systematically (and in ever increasing numbers) under-estimating the flows of investments due to ever more transactions falling below the reporting threshold.

Maybe the effects of the OECD's base erosion and profit shifting (BEPS) initiative and the tightening of national legislation seeking to curb round-tripping or the use of tax havens is creating a far more pronounced effect in statistics than we had assumed. Which would point more to a decade-long obliviousness to artificially over-expanded cross-border investment flows due to tax purposes, than a slow-down of economic activity or even de-globalization.

Finally, technological change is also having a significant impact on cross-border flows. Due to advanced manufacturing, 3D printing and robotics, the once unbeatable advantage of low-labour cost countries evaporates, and efficiency seeking FDI is losings its main driver. Similarly, the increasing "de-physicalization" of products (e.g., CDs and DVDs into stream-able files, maps into an APP on mobile devices) is converting products into bits $\&$ bytes which might cross borders, but whose economic value we are unable to measure. So simply because we cannot measure it, it does not exist?

So while there is undoubtedly a hardening of the policy context, and while the metrics with which we have-so far-measured globalization are indicating a slow-down, the jury is still out on whether we are truly living in less globally interconnected times, whether what we are seeing (or measuring) really is the harbinger of economic nationalism, or whether it isn't rather a new economic paradigm which so far we are unable to quantify.

This leads us to the second main theme of this year's AIB conference.

\section{Are We, the IB Field, Losing Relevance?}

Without too much of a stretch of imagination one can argue, that right now, this is the case. While we call ourselves international business, it is undisputed that the vast majority of the output we produce isn't read by either the business community or the political decision makers. Hence, it is hardly surprising that, as Boddewyn \& Rottig (2017: 3) remark, "we have failed so far to help our stakeholders-students, managers and policy-makers-make sense of our constantly changing world." The dramatic part of this is, that this isn't new. Ten years ago, Cohen (2007) observed that academic, peer-reviewed journals aren't written for and certainly not read by practitioners.

\section{6 While we call ourselves international business, it is undisputed that the vast majority of the output we produce isn't read by either the business community or the political decision makers.}

At this year's AIB conference in Dubai, the same conclusions were reached-but then quickly and nonchalantly brushed aside with reference to the academic incentive system. There is no other way. Publish or perish - the omnipresent excuse on everyone's lips. But if our research output isn't read by, and doesn't seem to have any relevance to, business people or policymakers, what is it then really for? And as a long-term consideration, why should a large sector such as ours be financed by public funds if there is no discernible use to those who provide and sign off these funds? In our very own interest we should make sure that we are relevant, interesting, and useful to the business community and to policymakers.

Even if to us the benefits are obvious, we need to look at our work through the eyes of those we allegedly speak for. Looking at the typical IB journal article, why should business people bother to read our output? Cohen (2007) rightly remarked that we focus on methodology and theory, and-at best—add a sentence or two on practical application. More importantly, however, I would contend that we are not even talking about the things practitioners would be interested in. We largely produce replication studies of previous articles which, in turn, are dealing with highly theoretical issues that can somehow be linked to the great theories in our field. Few, if any, deal with practical, real-world problems.

This is largely due to what can and cannot be published in academic journals. While for the individual, publishing in 
A-journals is furthering his or her career (and hence, perfectly understandable), as a field this practice will lead us straight into a dead end. The shocking bit in all of this is that most of us see this danger, but merely shrug our shoulders and carry on. "The system can't be changed" is a frequent response, and this might or might not be the case. But in order to stay relevant, we simply have to find new and uncharted areas to research, and we need to engage with business people and political decision makers.

And therein, I would contend, lies the other problem. Do we actually want to do that?

A few weeks ago, I was privy to a celebrated and highly published academic explaining to an experienced and well-connected businessman that the question he raised is invalid and irrelevant, not least because it doesn't tie into the theories and models how business people are taking decisions. Would it not be a reasonable assumption that a businessman might have some insight into such things? So, apart from it being breathtakingly arrogant, it is precisely what Boddewyn and Rottig (2017), von Glinow (2017), and Doh (2017) are warning us of. It is the cutting oneself off from ones' own sources as well any interest of the purported end-user. This is a prime example of the elitist detachment that Collinson (2017) was taking about.

If we are serious about the much repeated mantra that relevancy and impact do indeed matter, it appears to be obvious that, "practitioners $[. .$.$] are the best source of research questions$ of greatest urgency in the working world, as well as the data" (Garman, 2011: 131). Instead of continuing to ignore practical questions and continue on our quest to hunt for "gaps in the literature," slicing extant research into narrower and narrower hypothetical questions that have lost all relevance and connection to reality, we ought to bridge the by now sizeable gap between the concern of practitioners and the output of researchers. The gap between theory and practice. If we want to be relevant, we ought to think research questions from the end-user. How do we add value for these people? What are the questions that keep them up at night? And - a healthy dose of self-interest-how do we ensure that our output enters into the public debate?

\section{What Does This Mean for Our Field?}

So what does this mean for our field? And why should times of trouble-where globalization might or might not be under threat-be a second breath of life for IB?

We are not the only ones who are feeling the heat. Increasingly, there is a complicated and confusing world out there; one which raises more questions than ever before. Business people and policymakers are desperately looking for answers. And, if we are willing to rise to the challenge and deal with real-world problems, rather than the slightly narcissistic navel-gazing of our own pet theories, there is an eager readership waiting out there for those who, with a birds-eye view, might make sense of the messy world they find themselves in. Business people and politicians are as confused and worried by the question of whether we are experiencing another era of de-globalization as we are; they are wondering - as many of us do-whether history is repeating itself. Merely being part of the effort to seek to answer this question should drive our field right into the epicentre of decision makers' interest.

But for that we need to speak to business people and to political opinion leaders; we need to leave "our ivory towers" (von Glinow, 2017) and walk the production halls, trading rooms, and ministerial corridors. Just ask yourself, when was the last time you asked a business person what they are concerned about? Not a narrowly defined survey question, where on a Likert scale they could tick a box-but an open-ended question of what they consider to be important? Collinson (2017) is absolutely right in noting that we need "a clearer understanding of the processes, practices, and policies" that guide practitioners' lives. We need to ensure that our output is read not just by a handful of fellow academics but by those who, and for whom, we profess to research. For that, we need to chart a fuller, a more realistic picture, we need to work interdisciplinary.

And, we might need to re-think some of our theories. If one of the hallmarks of a globalized world is consistently low inflation rates (imported deflationary effects through a lower costbase), would the end of globalization then not result in the re-emergence of inflation? If digitization is changing the rules of the game and shortening global supply chains, would understanding IoT, LPWAN and OPC UA-things the business community is currently trying to get to grips with-not be a pre-requisite to be able to carry the debate?

The world is changing: global supply chains are in the process of being reconfigured, today's future markets might not be tomorrow's future markets, and the metrics that have served us well for decades are becoming more and more useless in a digitized world. And the fifteenth replication study of something we have known for a decade really isn't adding any useful answers (other than possibly being accepted for publication in an A-journal).

If we truly want to, and if we dare to step out of our self-chosen limitations, we might find ourselves right in the center of policy debate and in the spotlight of managers' interest, contributing our part to answers in this ever more complex world-a world which potentially is indeed becoming more restrictive and where international trade and investment are getting more difficult to navigate. But wouldn't that mean that high-quality intellectual input is more important than ever? 
If we come to the conclusion that we are in fact entering a period of de-globalization, the business community won't simply nod their head in acquiescence and accept that it is all over now, but they will want to have answers, and models, and ideas about "what next."

Operating internationally will probably always be possible, but more complex and expensive. Companies might, as Witt (2017) suggested, need more than one strategy. Sauvant (2013) observed that the rise of protectionism predates the financial crisis and might have more to do with a reassessment of nations of how they benefit from foreign investors.

As a field, we have to ask ourselves if we have potentially missed that phenomenon-just like economists didn't see the biggest financial crisis in a century coming. Should we then not hurry to get to grips with this new reality, rather than focus on the ever same old theories that led us to a point where we wonder whether we are, in fact, still relevant? Should understanding and explaining that new business environment not be the core of what our field is all about?

Seeking to answer the question of whether we are experiencing de-globalization and, if so, how to deal with its repercussions, should be a major boost for our field. And, if we are willing to engage with the business community and political opinions leaders, we might be finding the very raison d'étre we seemed to have been looking for so eagerly at our 2017 AIB annual meeting in Dubai.

\section{References}

Abbosh, O., Nunes, P. \& Ovanessoff, A. 2017. Adapting Your Digital Business to a Fragmented World. Accuenture Research.

Asmussen, C. G., Pedersen, T., Devinney, T. M., \& Tihanyi, L. 2011. Introduction to Part II: Dynamics of Globalization:Location-Specific Advantages or Liabilities of Foreignness? In Dynamics of Globalization: Location-Specific Advantages or Liabilities of Foreignness? p. 45-53.

Beugelsdijk, S., Hennart, J.-F, Slangen, A., \& Smeets, R. 2010. Why and how FDI stocks are a biased measure of MNE affiliate activity. Journal of International Business Studies, 41 (9): 1444-1459.

Boddewyn, J., \& Rottig, D. 2017. How to Regain Legitimacy and Relevance in a New Era for International Business: If Not Us, Who? AlB Insights, 17(2): 3-6.

Cohen, D. J. 2007. The very separate worlds of academic and practitioner publications in human resource management. Academy of Management Journal, 50(5): 1013-1019.

Collinson, S. 2017. The Declining Relevance and Legitimacy of IB Scholarship in a World That Really Needs It. AIB Insights, 17(2): 7-10.

Doh, J. 2017. Phenomenon-Based Research in International Business: Making IB Relevant Again. AIB Insights, 17(2): 14-16.
Garman, A. N. 201 1. Shooting for the Moon: How Academicians Could Make Management Research Even Less Irrelevant. Journal of Business and Psychology, 26(2): 129-133.

Ghoshal, S. 2005. Bad management theories are destroying good management practices. Academy of Management Learning and Education, 4(1): 75-91.

Sauvant, K. 2013. The rise of FDI protectionism. Columbia FDI Perspectives, http://ccsi.columbia.edu/files/2013/12/sauvant rise.pdf.

Sutherland, D., \& Anderson, J. 2015. The Pitfalls of Using Foreign Direct Investment Data to Measure Chinese Multinational Enterprise Activity. The China Quarterly, 221: 21-48.

Von Glinow, M. A. 2017. Plus a Change, Plus C'est La Même Chose? Or, That Was Then, This Is Now. AlB Insights, 17(2): 11-13.

Witt, M. A. 2017. The End of Globalisation? https://knowledge.insead. edu/economics-finance/the-end-of-globalisation-5046, accessed 11.07.2017.

Martin G. Kaspar (martin.kaspar@fraenkische-ip.com) is Head of Business Development at a German Mittelstands company within the Automotive industry and a PhD candidate at Durham University. He regularly contributes to practitioners magazines, has a column at fdi intelligence and is a regular speaker at FDI- \& digitalization-conferences, as well as IPA and Chamber of Commerce events. He has also been a speaker / participant at E15 Investment Facilitation events of the World Economic Forum, Ditchley Park, economic delegations, the Munich Economic Forum, UNCTAD and BoKoWiTa. 